\title{
ANALISIS METODOLOGI PENGAJARAN YANG DIAPLIKASIKAN KITAB AMTSILATI KARYA TAUFIQUL HAKIM DALAM MEMPELAJARI TATA BAHASA ARAB
}

Oleh:

Moh. Ali Ghafir ${ }^{1}$

Email: lazsidogiri_bangkalan@yahoo.com

\begin{abstract}
Amtsilati is one of the Arabic grammar books which has special characteristics compared to other books. This book is intended so that students can master in reading and giving meaning to the yellow book even though it is only a beginner level. This book does not target students to be able to communicate using Arabic, because the method is only emphasizing reading and giving meaning to the yellow book. There are several learning methods that were applied when the Amtsilati instructor, including: lecture methode, question and answer, discussion, memorization, takrar (repeating material) and qiraah jama'iyah (reading collectively). The system of compiling the discussion material in the book Amtsilati begins with a discussion of the jar, isim dhamir, isim isyarah and so on. While the method of presenting the material follows the method of Tariqah al-istiqraiyah or the research method (inductive), that is by providing examples of material to be discussed, then analyzing the rules. Very different from the Arabic grammar books in general.
\end{abstract}

Keywords: Amtsilati, teaching, nahwu, yellow book

\section{Pendahuluan}

Khalifah Umar Bin Khatthab RA berkata: "Belajarlah Bahasa Arab, karena Bahasa Arab itu dapat menambah kecerdasan dan harga diri". Sayyidina Umar Bin Khatthab RA pernah bertemu sekelompok orang sedang latihan menembak (memanah), mereka selalu salah sasaran dalam melepaskan panahnya, lalu beliau berkata: "luruskanlah panahmu", mereka menjawab: "kami sedang belajar memanah". Umar mendengar jawaban mereka dan ia berkata lagi, "kesalahan ucapanmu (dalam i'rab) lebih jelek dari pada hasil

${ }^{1}$ Dosen Prodi Pendidikan Bahasa Arab STAI Syaichona Moh. Cholil Bangkalan 
panahmu".2 Perkataan Umar tersebut memberi motivasi dalam belajar Bahasa Arab dan yang berkaitan dengannya, seperti ilmu gramatika Arab (nahwu dan sharraf) dan lainnya.

Bahasa Arab merupakan bahasa al-Qur'an dan hadits Nabi. AlQur'an merupakan salah satu kitab Allah yang paling agung di antara beberapa kitab Allah yang diberikan pada nabi-Nya. Rasulullah yang menjadi sayyidul anbiya' menggunakan Bahasa Arab dalam setiap berkomunikasi. Bahkan penduduk surga berbahasa Arab dalam mengekspresikan (mengungkapkan) isi hatinya antarsatu dengan lainnya. Nabi Muhammad bersabda: "Saya mencintai Arab karena tiga faktor, yaitu: karena saya sebagai orang Arab, bahasa al-Qur'an menggunakan Bahasa Arab, penduduk surga menggunakan Bahasa Arab". ${ }^{3}$

Untuk mempelajari Bahasa Arab diperlukan sarana-sarana (seperangkat alat) yang berkaitan dengan bahasa itu, seperti ilmu nahwu dan sharraf disamping pula mengusai kosa kata (mufradat) Bahasa Arab. Teks-teks Arab (kitab) yang "gundul" (tanpa harakat) dapat dipahami apabila menguasai Bahasa Arab dan sarana pendukungnya (nahwu dan sharraf). Tanpa menguasai sarana itu akan mengakibatkan salah dan keliru dalam memahami dan membaca redaksi tersebut. Salah dalam membaca akan mengakibatkan salah dan keliru dalam pemaknaan. Untuk menghindari hal itu, maka sarana ilmu nahwu dan sharraf menjadi suatu kebutuhan yang tidak boleh diabaikan. Sebagaimana teguran sahabat Umar Bin Khatthab RA pada sekelompok pemanah yang sedang belajar memanah, jawaban mereka dianggap keliru dalam segi i'rabnya oleh sahabat Umar Bin Khatthab RA.

Pada akhir-akhir ini, banyak keluhan dari pengasuh pondok pesantren tentang krisisnya kader-kader ulama yang menguasai ilmu tata Bahasa Arab. Generasi muda muslim mulai jenuh terhadap metode dan materi yang diajarkan di lembaga-lembaga pendidikan Islam tentang ilmu gramatika Arab pada umumnya. Di samping itu, mempelajari gramatika

${ }^{2}$ Abdur Rahman al-Makudi, Ibnu Hamdun bin al-Haj,Juz I, Dar al-Fikr, hlm. 17

${ }^{3}$ Syaikh Hasan al-Kafrawi, Alkafrawi Ala Matn al-Ajurumiyah, Al-Hidayah, hlm.2 
Arab ini harus ditempuh dengan waktu yang relatif lama, mereka sudah mulai disibukkan dengan mendalami ilmu-ilmu yang lain. Pelajar muslim tersebut harus diberi solusi agar tetap bisa menguasai Bahasa Arab, bisa baca kitab kuning dan ilmu tata Bahasa Arab.

KH Taufiqul Hakim dari Jepara melalui karya tulisnya yang bernama kitab Amtsilati mencoba memberikan solusi. Kitab Amtsilati Program Pemula Membaca Kitab Kuning ini mempunyai metode-metode khusus yang berbeda dengan kitab tata Bahasa Arab lainnya. Di samping itu, kitab ini dikemas dengan penyusunan materi pembahasan tata Bahasa Arab yang tidak sama dengan kitab yang lain pula. Sedikit demi sedikit kitab ini mendapat sambutan dari masyarakat. Kitab yang dibedah pada hari Minggu tanggal 16 Juni 2002 M/6 Rabi'us Tsani 1423 H ini, pada cetakan pertama (tahun 2002) dicetak sebanyak 300 set, kemudian meningkat menjadi 1000 set, dan pada 1 Agustus tahun 2004/15 Jumadis Tsani 1425 sudah tercetak sebanyak 3 juta exemplar. ${ }^{4}$ Lembaga-lembaga pendidikan Islam sudah mulai banyak yang meninggalkan kitab tata Bahasa Arab lainnya, dan memakai kitab Amtsilati sebagai kurikulum tetap.

Kitab ini mempunyai koordinator yang bertugas sebagai distibutor di beberapa wilayah di kawasan nusantara, yang terdiri dari wilayah Jakarta, Jawa Barat, Jawa Tengah, Jawa Timur (Madura), Sumatra, Kalimantan, dan Sulawesi. Ada apa di balik melonjaknya cetakan pada kitab ini ? Mengapa kitab ini banyak peminatnya?

\section{Objek Kajian}

Berawal dari pengalaman menjadi santri di Pondok Pesantren Maslakul Huda Kajen Margoyo Pati Jawa Tengah, dan bersekolah di Perguruan Islam Mathali'ul Falah di bawah asuhan KH Sahal Mahfudz dan KH Abdullah Salam, pengarang kitab Amtsilati merasakan begitu sulitnya membaca kitab kuning. Hal tersebut sangat wajar sebab latar belakang pendidikan Taufiqul Hakim sebagai penulis Amtsilati, dimulai dari TK, SD, $\mathrm{MTsN}$ yang notabene sangat minim pelajaran agama, apalagi tentang ilmu tata Bahasa Arab.

${ }^{4}$ Taufiqul Hakim, Tawaran Revulusi Sistem Pendidikan Nasional, PP. Darul Falah, Jepara, hlm.10 
Persyaratan yang harus dipenuhi adalah hafal nadzam Alfiyah, salah satu kitab yang membahas ilmu tata bahasa dengan memakai kalam nadzam. Dengan sekuat tenaga Taufiqul Hakim menghafalkannya walaupun belum tahu untuk apa Alfiyah itu, yang penting ia mantap dan yakin.

Suatu hari Taufiqul Hakim ingat pada sistem belajar cepat baca alQuran yang bernama Qira'ati. Terdorong dari metode Qira'ati yang mengupas cara membaca kalimat yang berharakat, ia ingin menulis kitab yang dapat dibuat pegangan untuk pembelajaran membaca kalimatkalimat yang tidak berharakat seperti kitab kuning. Mulai hari Minggu tanggal 27 Rajab tahun 1422 H/14 Oktober 2001 M, ia mulai merenung dan muncul pikiran untuk mujahadah. Ritual keagamaan itu berakhir sampai hari Minggu tanggal 17 Ramadhan 1422 H/2 Desember 2001 M. Di tengahtengah bermujahadah tersebut ia menulis kitab Amtsilati, dan akhirnya tepat hari Rabu tanggal 27 Ramadhan 1422 H/12 Desember 2001 M selesailah penulisannya dalam bentuk tulisan tangan dengan waktu selama sepuluh hari. Kemudian tulisan itu diketik dengan memakai tulisan komputer. Proses pengetikan memakan waktu satu tahun, lalu dicetak sebanyak 300 eksemplar. Sampai follow up tertulisnya Amtsilati, lalu digelar bedah buku di gedung NU Kabupaten Jepara pada Minggu tanggal 6 Rabius Tsani 1423 H/ 16 Juni tahun 2002. Pada tahun yang sama kitab ini dicetak lagi sebanyak 1000 eksemplar, dan sampai tanggal 15 Jumadis Tsani 1425/1 Agustus 2002 Amtsilati sudah tercetak sebanyak tiga juta eksemplar.

\section{Unsur-Unsur Kitab Amtsilati dan Materi Pembahasannya}

Kitab ini terdiri dari 5 jilid, yaitu Amtsilati jilid I-V dan ditambah dengan kitab pelengkap yang terdiri dari Khalashah, Tatimmah I dan II, Qa'idati, dan Sharfiyah dengan uraian berikut ini:

a) Amtsilati jilid I; membahas tentang huruf-huruf jar, pengaruh huruf jar pada kata tunggal, pengaruh huruf jar pada gabungan dua kata, pengaruh huruf jar pada kata yang mudhaf ilaihnya diakhiri ya', nun jamak, dhamir, isim isyarah, dan isim mausul. 
b) Amtsilati jili II; membahas tentang tanda-tanda isim, nakirah dan ma'rifat, mudzakar dan muanats, isim tatsniyah, jamak mudzakar salim, jamak muannats salim, wazan-wazan isim fa'il, isim maf'ul, dan masdar yang mazid.

c) Amtsilati jilid III; membahas tentang mubtada'-khabar, amil nawasikh, isim ghair al-munsharif, isim musytaq, isim tafdhil, mubalaghah, isim zaman, isim makan, isim alat, tashghir, masdar mim, nisbah, tawabi' dan isim jamid.

d) Amtsilati jild IV; membahas tentang fi'il madhi, macam-macam bentuk fi'il madhi, fa'il dzahir dan fa'il dhamir, wazan-wazan fi'il madhi, fi'il madhi mabni majhul, maf'ul bih, dharaf, maf'ul muthlaq atau masdar, maf'ul li ajlih, hal, dan tamyiz.

e) Amtsilati jilid V; membahas tentang fi'il mudhari', fa'il dhahir dan fa'il dhamir, fi'il mu'tal, wazan fi'il mudhari' mazid, fa'il dhamir dari mudhari' yang diawali dengan ya', nun taukid, mudhari' yang dibaca nasab, af'alul khamsah, mudhari' yang dibaca jazm, syarat dan jawab, huruf syarat, fi'il amar, fi'il amar yang mu'tal dari madhi tiga huruf, khabar jumlah, shilah mausul, hal dan sifat.

f) Khalashah; berisikan nadzaman Alfiah yang dibuat dasar-dasar atau dalil tata Bahasa Arab yang dipakai Amtsilati. Kitab ini terdiri dari 184 bait Alfiah, serta diterjemah ke dalam Bahasa Indonesia dan Bahasa Jawa dalam bentuk kalam nadzam.

g) Tatimmah jilid I; untuk menganalisis kata yang bisa menjadi bermacam-

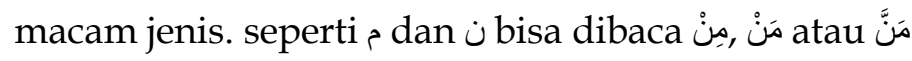

h) Tatimmah jilid II; menerangkan tentang tata cara merangkai kata atau kalimat sehingga membentuk suatu kalimat yang sempurna dengan menggunakan aturan yang telah dirumuskan dalam kitab Qoidati dan Tatimmah I. Seperti lafadz آلح maka termasuk ciri dari isim, ada đil juga termasuk isim makrifat. Apabila ada isim makrifat di awal kalimat maka qaidahnya menjadi mubtada'. Dalam pengkajian Tatimmah I bila iَ dibuang maka huruf yang tertulis ada tiga (حمد) setelah dibahas ternyata bisa menjadi fi'il dan isim, karena ada iا maka fi'il gugur. 
i) Sharfiyah; mengkaji setiap kata dengan mengkiaskan pada kata yang sejenis dalam bentuk wazan dan bayangan dlomirnya (هي هو), dengan melihat kebutuhan kalimat.

j) Qa'idati ; Merupakan intisari pengajaran kitab Amtsilati dari jilid 1-5.

\section{Pembelajaran Amtsilati}

1. Proses Pembelajaran Amtsilati

Proses perencanaan sistem pembelajaran ilmu tata Bahasa Arab Amtsilati diawali dengan pembacaan bait-bait yang ada di Khalashah, materi yang ada di Sharfiyah, Tatimmah, dan lainnya. Pengulangan ini dipandu oleh seorang pembimbing, dan dibaca secara kolektif. Pengulangan ini bertujuan agar materi-materi yang sudah diterima murid pada PBM sebelumnya tidak terlupakan. Biasanya takrar ini memerlukan waktu kirakira 10 menit.

Setelah pelaksanaan takrar selesai, maka pembimbing memulai pembelajaran materi baru sesuai dengan program yang telah ditentukan. Setiap jilid Amtsilati sudah mempunyai perencanan pembelajaran. Amtsilati jilid 1 diprogramkan bisa tuntas pembahasannya selama 10 hari. Jilid 2 diajarkan selama 10 hari, Amtsilati 3 memerlukan waktu selama 25 hari, jilid 4 proses belajar mengajarnya memerlukan waktu 15 hari, dan Amtsilati jilid 5 diajarkan selama 15 hari.Perpindahan dari jilid 1 pada Amtsilati berikutnya melalui evaluasi tahriri dan syafawi yang sudah ditetapkan.

Setelah siswa dapat menuntaskan semua Amtsilati dari jilid 1-5, maka materi yang diberikan pada murid adalah prapraktik. Prapraktik ini sifatnya adalah mengulang semua materi dari Amtsilati jilid 1-5 dalam segi hafalan (syafawi) dan hal yang berkaitan. Prapraktik ini memerlukan waktu selama 25 hari, dan setelah itu pembimbing Amtsilati ini memberi materi praktik baca kitab kuning. Praktik ini ditekankan pada belajar untuk memberi harakat dan memberi makna. Murid diusahakan dapat menguasai dua hal serta dapat menjelaskan dasar-dasarnya atau dalilnya. Selama kurang lebih tiga bulan pembimbing mengajar muridnya praktik baca dan pemaknaan pada kitab kuning. Setelah anak didik menguasai (tingkat pemula) baca kitab kuning dan memaknai, maka ia diberi 
syahadah atau sertifikat yang ditanda tangani oleh pengarang kitab Amtsilati.

PBM dalam Amtsilati terdiri dari empat jalsah sebagaimana pada tabel berikut ini.

Tabel 1 Jadwal Proses Belajar Mengajar dalam Program Amtsilati

\begin{tabular}{|c|c|c|}
\hline Jalsah & Jam Masuk & Keterangan \\
\hline I & $08.30-10.00$ & Penyampaian materi baru \\
\hline II & $10.00-11.00$ & Penyampaian materi baru \\
\hline III & $13.30-15.00$ & Penyampaian materi baru \\
\hline IV & $15.30-16.30$ & Penyampaian materi baru \\
\hline
\end{tabular}

Empat kali pertemuan ini memerlukan waktu 45 menit/jalsah, dengan perincian 10 menit pertama mengulangi Qa'idah pelajaran sebelumnya, 25 menit penambahan materi, 10 menit terakhir menghafalkan Qaidah dari pelajaran yang baru diajarkan. ${ }^{5}$

Selain dari pada jadwal PBM, anak didik diwajibkan menghafalkan materi-materi yang telah ditentukan, ekstra kurikuler ini dilaksanakan pada malam hari jam 20.00-21.00. Proses pembelajaran Amtsilati diprogramkan memerlukan waktu selama 3 bulan 10 hari dan ditambah waktu praktik baca dan pemaknaan kitab kuning selama 3 bulan.

2. Tujuan Pembelajaran Amtsilati

Tujuan pembelajaran merupakan elemen sistem pembelajaran yang sangat menentukan terhadap pola kerja elemen-elemen sistem pembelajaran yang lain. Tujuan pembelajaran merupakan pemimpin bagi semua unsur dalam sistem pembelajaran.

Amtsilati merupakan salah satu kitab tata Bahasa Arab yang mempunyai ciri-ciri khusus dibandingkan kitab yang lain. Kitab ini bertujuan agar anak didik dapat menguasai dalam membaca dan memberi makna kitab kuning meskipun hanya tingkatan pemula. Kitab ini tidak menargetkan anak didiknya dapat berkomunikasi dengan menggunakan

${ }^{5}$ Taufiqul Hakim (2004), Tawaran Revulusi,PP Darul Falah, Jepara. hlm. 14 
Bahasa Arab, karena metode yang ada hanya penekanan pada membaca dan memberi makna kitab kuning.

3. Metode Pembelajaran Amtsilati

Ada beberapa metode pembelajaran yang diaplikasikan pada saat pembimbing mengajar Amtsilati, diantaranya adalah: metode ceramah, tanya jawab, diskusi, hafalan, takrar (mengulang-ngulang materi) dan qiraah jama'iyah (membaca secara kolektif).Tetapi dalam penerapannya di kelas-kelas, pembimbing lebih sering menggunakan metode ceramah, hafalan, takrar dan qiraah jama'iyah.

Dalam metode qiraah jama'iyah yang diaplikasikan kitab Amtsilati dipandu pembimbingnya membaca contoh-contoh yang ada dalam kitab tersebut dan dilengkapi dengan dasar-dasar atau dalil yang diambil dari Khalashah. Dalam menyajikan dasar-dasar ini penulis menemukan metode khas yang diaplikasikan kitab Amtsilati disamping metode qiraah jama'iyah, yaitu takrar. Tahapan-tahapan proses belajar mengajar Amtsilati adalah: (1) mengulangi materi yang sebelumnya dengan durasi waktu 10 menit (2) memulai materi baru dengan cara guru dan murid membacanya secara bersama-sama contoh-contoh yang berkaitan dengan materi yang akan dibahas, serta menganalisisnya dalam segi kaidahnya, dengan durasi waktu 25 menit (3) menghafalkan Qoidah dengan durasi waktu 10 menit (4) evaluasi

\section{Evaluasi Hasil Belajar Amtsilati}

Anak didik yang akan naik pada jenjang jilid Amtsilati yang lebih tinggi harus melalui evaluasi. Evaluasi yang diterapkan Amtsilati terdiri dari dua macam evaluasi, yaitu evaluasi syafawi (hafalan) dan tahriri (tes tulis). Sebelum murid mengikuti evaluasi tahriri harus mengikuti evaluasi syafawi.

Evaluasi syavawi adalah menghafalkan materi-materi yang ada pada jilid sebelumnya yang terdiri dari Khalashah, Qa'idah, Sharfiyah dan Tatimmah. Evaluasi syafawi (hafalan) sebenarnya dilaksanakan setiap malam hari yang dipandu oleh pembimbing, dan guru menyediakan kartu khusus untuk tanda bukti batasan yang dihafalkan. Bagi anak didik yang sudah hafal dengan baik, ia berhak minta paraf pada pembimbingnya. Nilai evaluasi syafawi harus bernilai 10 . 
Sedangkan evaluasi tahriri adalah tes tulis yang diambilkan dari materi sebelumnya. Dalam evaluasi ini bentuk soalnya ditekankan pada penerapan, sedangkan anak yang bisa naik pada jilid selanjutnya harus mendapat nilai minimal 9,1. Bagi anak yang tidak sampai pada target nilai ini maka harus mengulang lagi. Waktu evaluasi dua kali dalam seminggu yaitu hari Senin dan Kamis. ${ }^{6}$

Sistem yang dianut Amstilati berbasis kompetisi dan kompetensi. Anak yang pandai akan cepat menyelesaikan materi-materi yang ada, anak yang bodoh akan menjadi matang walaupun memerlukan waktu lama. ${ }^{7}$

5. Praktik Amtsilati

Praktik adalah penerapan materi-materi yang sudah diterima dan dikuasai oleh murid. Praktik ini diperuntukkan bagi siswa yang sudah hatam semua jilid Amtsilati dan ditambah Qaidah, Sharfiyah, dan Tatimmah. Praktik merupakan puncak dari PBM Amtsilati. Dalam praktik ini murid dilatih membaca kitab kuning serta memberi makna pada kitab itu. Disamping itu anak didik Amtsilati ini dilatih untuk mencari makna kosa kata dalam kamus yang sudah disediakan. Makna yang dipergunakan dalam belajar memberi makna adalah Bahasa Jawa.

\section{Sistematika Penyusunan Materi dalam Kitab Amtsilati}

Amtsilati merupakan materi pembelajaran bagi pemula, baik pemula kanak-kanak atau pemula kawak-kawak (tua). Contoh-contoh yang ditampilkan simpel, ringan, diulang-ulang terus-menerus dalam contoh yang berbeda-beda dalam pembahasan yang sama. Kitab selain Amtsilati selalu memberi contoh خَاءَ زَيْدُ (Zaid sudah datang), ضَرَبْتُ زَيْدًا (Saya sudah mukul Zaid) dan lainnya. ${ }^{8}$ Dalam Amtsilati dituliskan contoh-contoh yang diambil dari al-Quran, dengan beraneka ragam contoh, sehingga tidak menyebabkan anak didik jenuh.

Sistematika penyusunan materi dalam kitab Amtsilati diawali dengan pembahasan tentang (1) huruf jar, (2) isim dhamir (3) isim isyarah (4) isim

6 Taufiqul Hakim, (2004), Tawaran Revulusi, PP Darul Falah, Jepara, hlm.14

7 Ibid, hlm. 18

${ }^{8}$ Ibid, op.cit 
mausul (5) tanda-tanda isim (6) macam-macam isim (7) wazan-wazan isim fa'il (8) wazan-wazan isim maf'ul dan seterusnya.

Sedangkan metode pengajarannya dengan cara menyajikan contohcontoh yang berkaitan dengan materi yang akan dibahas, kemudian dianalisis. Dalam kitab karya Taufiqul Hakim ini sedikit teori dan banyak praktik. Metode ini dianggap lebih efektif, karena anak didik langsung dikenalkan dengan inti permasalahan. ${ }^{9}$

Kitab Amtsilati menganut metode thariqah al-istigraiyah atau metode penelitian (induktif), yaitu: menyajikan contoh-contoh, lalu menganalisisnya tentang contoh itu berdasarkan kaidah tata Bahasa Arab. Pengajaran dengan metode ini tergolong memulai dari yang khusus pada yang umum. ${ }^{10}$

Pembahasan dalam Amtsilati diawali dengan membahas hurufjar (bab huruf jar) karena anak yang belajar kitab ini tergolong pemula. Sedangkan pemula dibayangkan belum bisa berbicara, maka pelajaran yang disampaikan adalah hal-hal yang kecil dan sederhana.

Setelah pembahasan huruf jar, materi yang dibahas adalah isim dhamir karena dhamir itu sederhana, dan mabni sehingga pikiran anak didik selalu tetap dan tidak goyah. Secara filsafat, dhamir berjumlah 12 yang terbagi dalam tiga kelompok yaitu: mutakallim, mukhathab dan ghaib. Arti angka 12 menjadi lambang: sehari 12 jam, semalam 12 jam, dan setahun berjumlah 12 bulan. Kalimat tauhid berjumlah 12 huruf, Muhammad al-Rasulullah berjumlah 12 huruf juga. ${ }^{11}$

\section{Contoh Metode Takrar dalam Islam}

Metode takrar bukan hal yang baru dalam Islam, seperti berikut ini:

1. Rasulullah Saw pernah bersabda dalam sebuah haditsnya yang diriwayatkan oleh Abi Hurairah RA. Pada saat itu ada seorang laki-laki menghadap Rasulullah seraya berkata, "Berilah aku nasihat", dan Nabi

${ }^{9}$ Ibid, op.cit

${ }^{10}$ Azhar Arsyad (1998), Madkhal Ila Thuruq Ta'lim al-Lughah al-Ajnabiyah, Ujung Pandang. hlm.131

${ }^{11}$ Ibid, op.cit 
menjawabnya, "Jangan marah". Ucapan Nabi ini diulangi beberapa kali. ${ }^{12}$

2. Para sahabat pernah bertanya pada Rasulullah, "Pada siapakah aku harus berbakti? Nabi menjawab "ibumu", lalu siapa? Dijawab lagi oleh Nabi "ibumu", lalu siapa? Nabi menjawab "ayahmu.13

3. Sayidina Mu'adz dan Jabir berkata, bahwa pada saat Rasulullah naik ke langit yang ketiga menjumpai malaikat dalam posisi bersujud, ia tidak pernah bangun dari sujudnya kecuali pada saat Nabi memanggil salam padanya. Malaikat itu bangun untuk sekedar menjawab salam Nabi, lalu ia sujud kembali. Dengan kasus inilah, sujud dalam shalat mengalami takrar (dua kali). ${ }^{14}$

4. Ada sebagian ulama mengatakan, mengaji satu huruf harus ditakrar sebanyak seribu kali", ${ }^{15}$ Hammad bin Ibrahim berkata, "Apabila kamu sudah hafal sesuatu maka ulang-ulanglah dan apabila sudah tidak mungkin terlupakan, maka belajarlah materi yang lain sambil lalu mengulangi materi-materi yang sebelumnya". ${ }^{16}$

5. Metode takrar sering juga ditemukan dalam al-Qur'an, seperti dalam

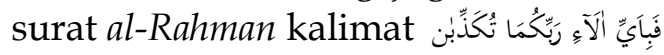

\section{Simpulan}

Sistem penyusunan materi pembahasan dalam kitab Amtsilati diawali dengan pembahasan tentang huruf jar, isim dhamir, isim isyarah dan seterusnya. Sedangkan metode penyajian materi mengikuti metode thariqah al-istiqraiyah atau metode penelitian (induktif), yaitu dengan cara memberikan contoh-contoh materi yang akan dibahas, kemudian dianalisis tentang kaidah-kaidahnya. Sangat berbeda dengan kitab-kitab gramatika Arab pada umumnya. Metodologi pengajaran yang menjadi ciri khas dan sering diaplikasikan kitab Amtsilati adalah metode takrar (pengulangan hlm.54

2 Yahya bin Syarfuddin, Syarh al-Arba 'in al-Nawawi, Alhidayah, Surabaya,

${ }^{13}$ Ibnu Majah, Sunan Ibn Majah, Mauqi'ul Islam, Juz 11, hlm.49

${ }_{15}^{14}$ Muhammad Nawawi, Sullam al-Munajat, Alhidayah, Surabaya. hlm.22

15 Azzarnuji, Tailim al-Muta'alim (terj. Baghdad al-Maliki), Al-Hidayah, Surabaya. hlm.57

${ }^{16}$ Ibid. 
kaidah-kaidah materi), hafalan, dan membaca dengan kolektif (qiraah jama'iyah). 


\section{DAFTAR PUSTAKA}

Arikunto, Suharsini. 1995. Manajemen Penelitian. Jakarta: Rineka Cipta.

Arsyad, Azhar. 1998. Madkhal ila Thuruqi Ta'lim al-Lugah al-Ajnabiyah. Ujung Pandang: Al-Ahkam.

Arsyad, Azhar. 2004. Bahasa Arab Dan Metode Pengajarannya (Yogyakarta: Pustaka Pelajar.

Danim, Sudarwan. 1997. Metode Penelitian Untuk Ilmu-Ilmu Perilaku. Jakarta: Bumi Aksara.

Dirjosoemarto, Soenjoyo. 1980. Pengertian dan Fungsi Media Pendidikan. Jakarta: P3G Depdikbud.

Furchan, Arif. 2005. Pengantar dalam Pendidikan. Surabaya: Usaha Nasional.

Ghazali, M. Bahri. Pesantren Berwawasan Lingkungan. Jakarta: Prasastra.

Hakim, Taufiqul. 2003. Amtsilati. Jepara: Alfalah Offset.

Hamalik, Oemar. Kurikulum Dan Pembelajaran. Jakarta: Bumi Aksara.

Hilmi, Irfan. 2003. Modernisasi Pesantren. Bandung: Nuansa.

Ibrahim, Abdul Alim. 1962. Al-Muwajjih al-Fanny li Mudarrisiy al-Lugah alArabiyah. Mesir: Dar al-Ma'arif

Jamarah, Syaiful Bahri dan Aswan Zain. 2006. Strategi Belajar Mengajar Jakarta: Rineka Cipta.

Kancana, Wayan Nur dan Sunartana. 1982. Evaluasi Pendidikan. Surabaya: Usaha Nasional.

LPSI. Guruku di Pesantren. Pasuruan: LPSI.

Margono, S. 1997. Metodologi Penelitian Pendidikan. Jakarta: Rineka Cipta. 
Muhaimin et al. 2001. Paradigma Pendidikan Islam. Bandung: Remaja Rosdakarya.

Najir, Muhammad. 1985. Metode Penelitian. Jakarta: Ghalia Indonesia.

Rofiq, Aunur. 2008. Ringkasan Kaidah-Kaidah Bahasa Arab. Gresik: Pustaka Al-Furqon.

Sanjaya, Wina. 2006. Strategi Pembelajaran. Jakarta: Kencana.

Sulaiman, Husen. 1969. Ta'lim al-Lugah al-Arabiyah. Mesir: Dar al-Ma'arif.

Syah, Muhibbin. 2007. Psikologi Pendidikan. Bandung: Remaja Rosdakarya.

Yunus, Fahmi Ali dan Mahmud Kamil. 1977. Asasiyaat Ta'lim al-Lugah alArabiyah. Qahirah: Dar ats-Tsaqafah.

Zuriyah, Nurul. 2007. Metodologi Penelitian Sosial dan Pendidikan. Jakarta: Bumi Aksara. 